\title{
Plunge cylindrical grinding with the minimum quantity lubrication coolant technique assisted with wheel cleaning system
}

\author{
Eduardo Carlos Bianchi ${ }^{1}$ (D) - Rafael Lemes Rodriguez ${ }^{1}$. \\ Rodolfo Alexandre Hildebrandt ${ }^{1}$ - José Claudio Lopes ${ }^{1} \cdot$ Hamilton José de Mello $^{1}$. \\ Rosemar Batista da Silva ${ }^{2}$. Paulo Roberto de Aguiar ${ }^{1}$
}

Received: 29 June 2017 / Accepted: 13 November 2017 / Published online: 1 December 2017

(C) Springer-Verlag London Ltd., part of Springer Nature 2017

\begin{abstract}
MQL technique is considered as a cleaner machining compared to the conventional coolant delivery one, thereby ensuring environmental sustainability and economic benefits. However, one of problems commonly reported when using the MQL technique is the wheel clogging phenomenon as a result of the inefficient chip removal from the cutting zone, then the chips lodge inside the pores of the grinding wheel, adversely affecting the quality and the finishing of the final product. In this context, this study was carried out to evaluate the performance of the minimum quantity lubrication coolant technique assisted with a wheel cleaning jet $(\mathrm{MQL}+\mathrm{WCJ})$ in plunge grinding of hardened steel. This cooling-lubrication technique was tested using the following flow rates: 30,60 , and $120 \mathrm{ml} / \mathrm{h}$. Comparative tests were also carried out with the conventional coolant technique, as well as with the traditional MQL technique (without the wheel cleaning jet). The output variables used to assess the efficiency of the MQL + WCJ technique are roughness, roundness, workpiece microhardness, grinding wheel wear, and power consumption. The results showed that the machining with the MQL + WCJ technique outperformed the traditional MQL technique in all the output parameters investigated. Also, the efficiency of the MQL + WCJ technique increased with flow rate, thereby being an alternative coolant delivery technique in grinding due to cleaner environment, more sustainable and lower consumption of fluid compared to conventional coolant one. No thermal damages and cracks on the machined surface and sub-surfaces were observed after grinding AISI 4340 steel, irrespective of the technique.
\end{abstract}

Keywords Cylindrical grinding $\cdot$ MQL technique $\cdot$ Wheel cleaning $\cdot$ Roughness $\cdot$ Surface integrity

\section{Introduction}

Grinding operation is employed in the machining process in order to provide a combination of good finishing (less than $1.6 \mu \mathrm{m}$ ) and accuracy (IT3-IT6) [1] to a machined part. Nguyen \& Butler [2] describe grinding operation as one of the finishing processes used in machining, whereby the grinding process comprehends low rate of material removal by an abrasive tool compared to the geometrically-defined cutting edge process.

There are some peculiar characteristics inherent to the grinding process in comparison to machining operations with
Eduardo Carlos Bianchi

bianchi@feb.unesp.br

Rafael Lemes Rodriguez

rodriguez.raaf@gmail.com

Rodolfo Alexandre Hildebrandt

hildebrandt@hotmail.com.br

José Claudio Lopes

jclaudio.lopes@hotmail.com

Hamilton José de Mello

hamilton@feb.unesp.br
Rosemar Batista da Silva

rosemar.silva@ufu.br

Paulo Roberto de Aguiar aguiarpr@ feb.unesp.br

1 Bauru campus, Department of Mechanical Engineering, São Paulo State University “Júlio de Mesquita Filho”, Bauru, Sao Paulo, Brazil

2 School of Mechanical Engineering, Federal University of Uberlandia, Uberlandia, MG, Brazil 
geometrically defined cutting edge, for example, the intense interaction between tool abrasives and workpiece, it can promote thermal damages by friction and plastic deformation. In general, the great amount of heat generated by the cutting action is directed to the workpiece due to the low thermal conductivity of conventional abrasives at high grinding temperatures and small sections of chips formed. If a portion of heat is not properly removed by means such as cutting fluid, the workpiece will be subjected to thermal damages (cracks, grinding burns, microstructure alterations and residual tensile stress) [3]. According to Sharma et al. [4], energy is consumed in chip formation via plastic deformation of workpiece and overcoming of friction because of mechanical and chemical action of grinding wheel, since abrasive wheel is being plunging against the workpiece at high speeds. The great amount of energy and high temperatures, which are constantly involved in grinding processes, affects the properties of abrasive grains too and can lead to a reduction of wheel service life [5].

In addition, the excessive quantity of generated energy in the grinding process can cause tool distortion, thereby adversely affecting the dimensional accuracy of the workpiece, so that the quality of finishing operation is limited [6]. In this context, cutting fluids are applied in order to minimize deleterious effects caused by excessive heat in the cutting zone [7]. Coolants play important roles in grinding as they can ensure cooling the workpiece and lubrication of the contact zone between workpiece and grinding wheel, as well as removing and cleaning chips from the cutting zone; as such, then the service life of wheel grinding is prolonged and the quality of workpiece is improved.

Despite the fact that technological advantages are evident with the usage of cutting fluids, some negative effects have been discussed in recent years [8]. High peripheral velocity and the fact that coolants are pressurized into the cutting zone under medium pressure during grinding can together lead to formation of mist and/or aerosol that are harmful to human health (affecting eyes, skin (dermatitis) and respiratory system (if they are inhaled) [9]. Moreover, not only is the disposal of cutting fluids waste complex, but also is their storage. The total cost with cutting fluids (including storing, filtering and disposal waste) in some cases is higher than tooling costs [10].

Aiming to substantially reduce the consumption of cutting fluids and their risks to human health, as well as to decrease environmental impacts caused by conventional machining process, Minimum Quantity Lubrication (MQL) technique was developed. This technique highlights among others, since dry machining with use of conventional grinding wheel has not provided satisfactory results in several works because of high amount of energy that is involved [11] that in general leads to burning of machined surface. Evidences of improvement in the grinding efficiency have been found in the literature with the use of the MQL coolant technique under particular experimental conditions, especially because of the better lubrication property in the grinding zone provided by the oil, thereby lower friction, in relation of the conventional coolant delivery technique $[4,10]$. The great advantage of this technique is the substantial reduction in flow rate employed $(600,000 \mathrm{ml} / \mathrm{h}$ to $240 \mathrm{ml} / \mathrm{h}$, which in turn represents a drop of $99.96 \%$ in volume), whereby hazards to employee and environment are reduced [12]. However, one of the drawbacks of the MQL technique is hot chips which are generated in grinding zone tend to lodge in the pores of the abrasive tool [13]. Cameron et al. [14] describe the wheel clogging phenomenon or the grout formation as: when the cutting fluid do not fully remove the chips generated in the grinding process from the cutting zone, chips mixes with oil and lodge in wheel pores impairing the entrance of the cutting fluid in the cutting zone; this fact hampers cooling and lubrication. The lodged chips increase the side flow plowing contribution to the total specific energy and lead to increase of amount of heat generated in the cutting zone, and consequently, the heat flux to the workpiece increases as well. Therefore, the process efficiency and quality are affected by the increase of the heat generated in cutting zone due to steady contribution of elastic and plastic deformation in total grinding energy.

Oliveira et al. [13] evaluated the efficiency of MQL technique assisted with the air compressed wheel cleaning for different angles of incidence in grinding operation. These authors concluded that the MQL technique with the cleaning compressed air jet (for a specific angle of incidence- $30^{\circ}$ ) provided the best performance the terms of the surface quality and accurate workpiece shape; moreover, this coolinglubrication technique resulted in reduction of the wheel wear in comparison to the other cooling-lubrication techniques (without the compressed air wheel cleaning).

Ramesh et al. [15] carried out a study in the development of coolant delivery system based on a chilled air (at a subzero temperature range of from -35 to $-30{ }^{\circ} \mathrm{C}$ and a flowrate of $400 \mathrm{~L} / \mathrm{min}$ ) with biodegradable oil and air mist (what they called chilled air/eco mist generation technology) as alternative method to conventional coolant technique (water-based coolant) in grinding operations of two grades of steel (a hardened ANSI 1045 and stainless steel ANSI 304). The chilled air and oil and air mist were delivered through two different ducts and then combined using a specially designed twincompartment nozzle. As a result, the authors found reduced grooves on the machined surfaces and, in some cases, inexistence of secondary plowing when the chilled air/eco mist coolant supply was applied, thereby preventing the occurrence of grinding burn. In other research, Ramesh et al. [16] developed a "metered quantity coolant" (MQC) nozzle that controls the amount of coolant delivered into the grinding zone by a controlled jet impingement in the cylindrical grinding ANSI 304 steel. The system was composed of a flow meter, a pressure gage, a manifold and changeable nozzles. They tested three different nozzles with cross-sectional areas of 15.14, 28.56, 
and $50.26 \mathrm{~mm}^{2}$, that resulted in the coolant velocity ranges of $3.6-9.9,2-12.3$, and $6-17 \mathrm{~m} / \mathrm{s}$, respectively, and found that the grinding performance was significantly affected by the coolant velocity and the following conclusion was drawn: if coolant velocity is low, coolant is unable to penetrate into the grinding zone and consequently, thus becoming ineffective to remove heat.

In order to explore the various potential health, environmental and economic benefits that have been widely reported in the literature about the use of MQL technique in grinding, this work aims to evaluate the performance of with the MQL assisted with the wheel cleaning system (MQL + WCJ) under several flow rates $(30,60$ and $120 \mathrm{ml} / \mathrm{h})$ in the plunge cylindrical grinding of AISI 4340 steel with an aluminum oxide wheel. The output parameters used to assess the performance of the MQL technique were roughness, roundness, microhardness of the workpiece surface, diametrical wheel wear, and power consumed. Images of the machined surfaces were also analyzed.

\section{Experimental procedure}

The experimental tests were carried out on a CNC cylindrical plunge grinding machine (RUAP $515 \mathrm{H}$ model). Specimens were manufactured in ring-shaped workpieces of AISI 4340 steel, quenched and tempered $(697 \mathrm{HV})$, with dimensions of $54 \mathrm{~mm} \pm 0.1 \mathrm{~mm}$ outer diameter, $30 \pm 0.1 \mathrm{~mm}$ internal diameter, and $4 \pm 0.1 \mathrm{~mm}$ thickness, as can be seen in Fig. 1 .

A white aluminum oxide abrasive wheel with $355.6 \mathrm{~mm}$ outer diameter, $127 \mathrm{~mm}$ internal diameter, $25.6 \mathrm{~mm}$ width, with vitrified bond, was used in the grinding tests. The grinding wheel was provided by NORTON Co abrasive wheel manufacturer. A summary of the machining conditions employed is presented in Table 1.

The MQL system is integrated by the following components: air compressor, pressure controller, flow measuring device and mixer nozzle. The pulsating system was comprised of a built-in intermittent oil supply, which allowed the separately controlled flow rate of compressed air and lubricant oil. A

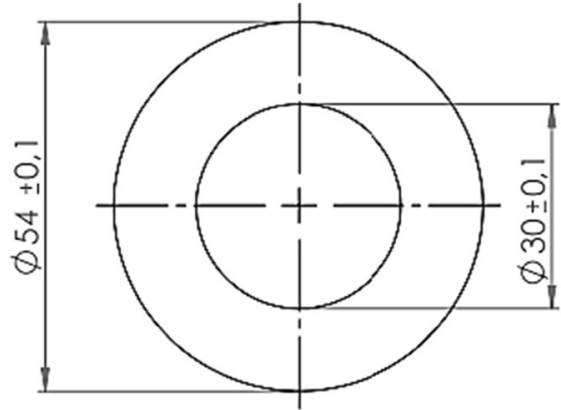

Fig. 1 Workpiece dimensions turbine flow meter was used in order to monitor the compressed air flow rate. Compressed air and MQL oil were delivered to the cutting zone through two hoses connected to a nozzle (MQL nozzle) positioned at a distance of $25 \mathrm{~mm}$ from the wheel-workpiece interface (Fig. 2a, c).

The wheel cleaning system is comprised of the following components: compressor, compressed air flow and pressure meter, flow distributor, and nozzle. The compressed air flow was monitored by a turbine flow meter and the nozzle of the cleaning system was attached at a distance of $5 \mathrm{~mm}$ (nozzle exit) from the wheel surface (Fig. 2a).

The grinding tests were carried out under the following different cooling-lubrication techniques: conventional coolant (flood), MQL Assisted with Wheel Cleaning Jet (MQL + WCJ) and traditional MQL (without wheel cleaning). Three different flow rates-30, 60, and $120 \mathrm{ml} / \mathrm{h}$-were employed in machining with the both MQL techniques. Three tests were carried out for each cooling-lubrication condition.

With regard the output parameters, the surface roughness Ra parameter was measured using Taylor Hobson Surtronic3+ portable stylus instrument. The measurements were taken using a cut-off of 0.25 and $1.25 \mathrm{~mm}$ sampling length. The measurement results correspond to the average of readings in three different positions $\left(120^{\circ}\right.$ spacing $)$ for each workpiece under the same cooling-lubrication condition. Similarly to the methodology adopted for measuring roughness, roundness error measurements were taken in all experiments with aid of a Taylor Hobson Talyrond 31C device. This equipment has a mobile arm supplied by a ruby ball which touches the workpiece in order to obtain the roundness error value.

The measurements of the workpiece were taken in a microhardness tester from Mitutoyo, HM-211 model. A load of $300 \mathrm{~g}$ during $40 \mathrm{~s}$ was used for a better view of indentation. In order to detect any alteration in the microstructure of the workpiece material, the specimens that presented the lowest standard deviation for roughness and roundness were selected and photographed with optical microscopy (Olympus BX-51) with $\times 500$ magnification.

With regard the wheel wear measurements, a cylindrical AISI 1020 steel workpiece was used for printing the wheel profile. This technique is widely employed because of the profile produced in the wheel surface during the grinding experiment can be printed on the soft steel cylinder. More detailed information about this technique can be found elsewhere $[13,17]$. The diametrical wheel wear was measured via profile projection and measurement with the aid of surface roughness meter software (Taylor Hobson TalyMap).

Grinding power was monitored through the acquisition of the energy consumed in the grinding machine axis by a sensor. A module Curvopower 3 transformed the voltage signals emitted by the spindle motor into power signals; this module, which collected instantaneously current, voltage and mean power signals, was connected to a BNC-2110 connector 
Table 1 Grinding conditions

\begin{tabular}{|c|c|}
\hline Grinding process & External cylindrical plunge grinding \\
\hline Grinding wheel & $\begin{array}{l}38 \text { A } 150 \text { L } 6 \text { V (white aluminum oxide grinding wheel with vitrified } \\
\text { bond) }\end{array}$ \\
\hline Cutting speed $\left(\mathrm{v}_{\mathrm{s}}\right)$ & $30 \mathrm{~m} / \mathrm{s}$ \\
\hline $\begin{array}{l}\text { Radial feed rate (vf) (specific } \\
\text { material removal rate) }\end{array}$ & $0.50 \mathrm{~mm} / \mathrm{min}\left(1.41 \mathrm{~mm}^{3} / \mathrm{s}\right)$ \\
\hline Work speed (vw) & $\mathrm{vw}=0.58 \mathrm{~m} / \mathrm{s}$ \\
\hline Effective depth of cut (ae) & $\mathrm{ae}=1.2 ; 2.5 ; 3.7 \mu \mathrm{m} / \mathrm{rev}$ \\
\hline Cooling-lubrication conditions & $\begin{array}{l}\text { Conventional technique (flood coolant), MQL }+ \text { WCJ technique and } \\
\text { traditional MQL technique (without wheel cleaning jet) }\end{array}$ \\
\hline \multirow[t]{3}{*}{ Conventional coolant Flow rates } & $\begin{array}{l}\text { Water miscible — semi-synthetic vegetable oil (at a concentration of } \\
2.5 \%)-\mathrm{ME}-2 \text { produced by Quimatic/Tapmatic }\end{array}$ \\
\hline & Conventional coolant technique: $450,000 \mathrm{~mL} / \mathrm{h}$ \\
\hline & MQL and MQL + WCJ: $30 \mathrm{~mL} / \mathrm{h}, 60 \mathrm{~mL} / \mathrm{h} ; 120 \mathrm{~mL} / \mathrm{h}$ \\
\hline MQL oil & $\begin{array}{l}100 \% \text { vegetable, biodegradable with viscosity of } 70 \mathrm{cSt}\left(25^{\circ} \mathrm{C}\right) \text { - } \\
\text { Accu-Lube LB } 1000 \text { produced by ITW Chemical }\end{array}$ \\
\hline $\begin{array}{l}\text { Velocity of compressed air in } \\
\text { cleaning }\end{array}$ & $470 \mathrm{~m} / \mathrm{s}$ \\
\hline Air pressure in MQL & $0.6 \mathrm{MPa}$ \\
\hline Angle of incidence & $30^{\circ}$ \\
\hline Air pressure in cleaning system & $0.7 \mathrm{MPa}$ \\
\hline Workpiece material & AISI 4340 steel, quenched and annealed (60 HRc $-697 \mathrm{HV})$ \\
\hline Dresser & Diamond cluster-volume of $15 \mathrm{~mm} \times 8 \mathrm{~mm} \times 10 \mathrm{~mm}$ \\
\hline Dressing depth (ad) & $\mathrm{ad}=0.200 \mathrm{~mm}(50$ cycles $-0.004 \mathrm{~mm}$ for each cycle $)$ \\
\hline Sparkout time (ts) & $\mathrm{ts}=8 \mathrm{~s}$ \\
\hline Dressing speed (vd) & $740 \mathrm{~mm} / \mathrm{min}$ \\
\hline
\end{tabular}

block. Then, the system was connected to a PCI-6035E DAQ board with 16-bit resolution and maximum data acquisition frequency of $200 \mathrm{kS} / \mathrm{s}$, both manufactured by National Instruments. The acquisition rate used to monitor the mean power signals was $2 \mathrm{kS} / \mathrm{s}$. The data were processed by the usage of the LabVIEW® platform.

\section{Results and discussion}

In this session, results and discussion are presented for the output variables previously mentioned in the methodology session.

\subsection{Surface roughness}

Surface finishing significantly affects the fatigue resistance of machined components, in special those that are subjected to work conditions with alternating stresses and high temperatures [1]. Thereby workpiece roughness has a direct connection with lubrication characteristics, depending on the shape of the abrasive grain, as well as the dressing conditions, feed rate, sparking time and cooling-lubrication conditions. Furthermore, in the machining process, more specifically in grinding, if lubrication and cooling functions of coolant are not satisfactory, more heat is generated to the cutting zone. This will cause generation of excessive temperatures and cause thermal damage to the workpiece, such as microstructural alteration, burning and residual tension, as well as geometric errors and quality deterioration of final workpiece produced.

Average of values of the Ra parameter $(\mu \mathrm{m})$ obtained after grinding under different cooling-lubrication conditions are shown in Fig. 3. All the roughness results were lower than $1.2 \mu \mathrm{m}$, below the stipulated rejection limit of $1.6 \mu \mathrm{m}$ for grinding operation commonly reported in the literature. Also, it can be seen from this figure that the lowest Ra values were recorded after machining under the conventional coolant technique. This is in contrast to results reported by Silva et al. [18], whose tests employed the same workpiece material in similar grinding conditions, with exception of the abrasive wheel (they employed a vitrified CBN grinding wheel). According to these authors, the superior performance of MQL technique in terms of roughness can be attributed to better lubrication property of the oil delivered into the wheel-workpiece interface, which lead to reduction of friction and higher grain sliding in contact zone.

Also, from Fig. 3 can be inferred that plunge cylindrical grinding of the AISI 4340 steel grade via the traditional MQL technique (without the wheel cleaning jet) exhibited inferior performance in terms of finishing when compared to the 


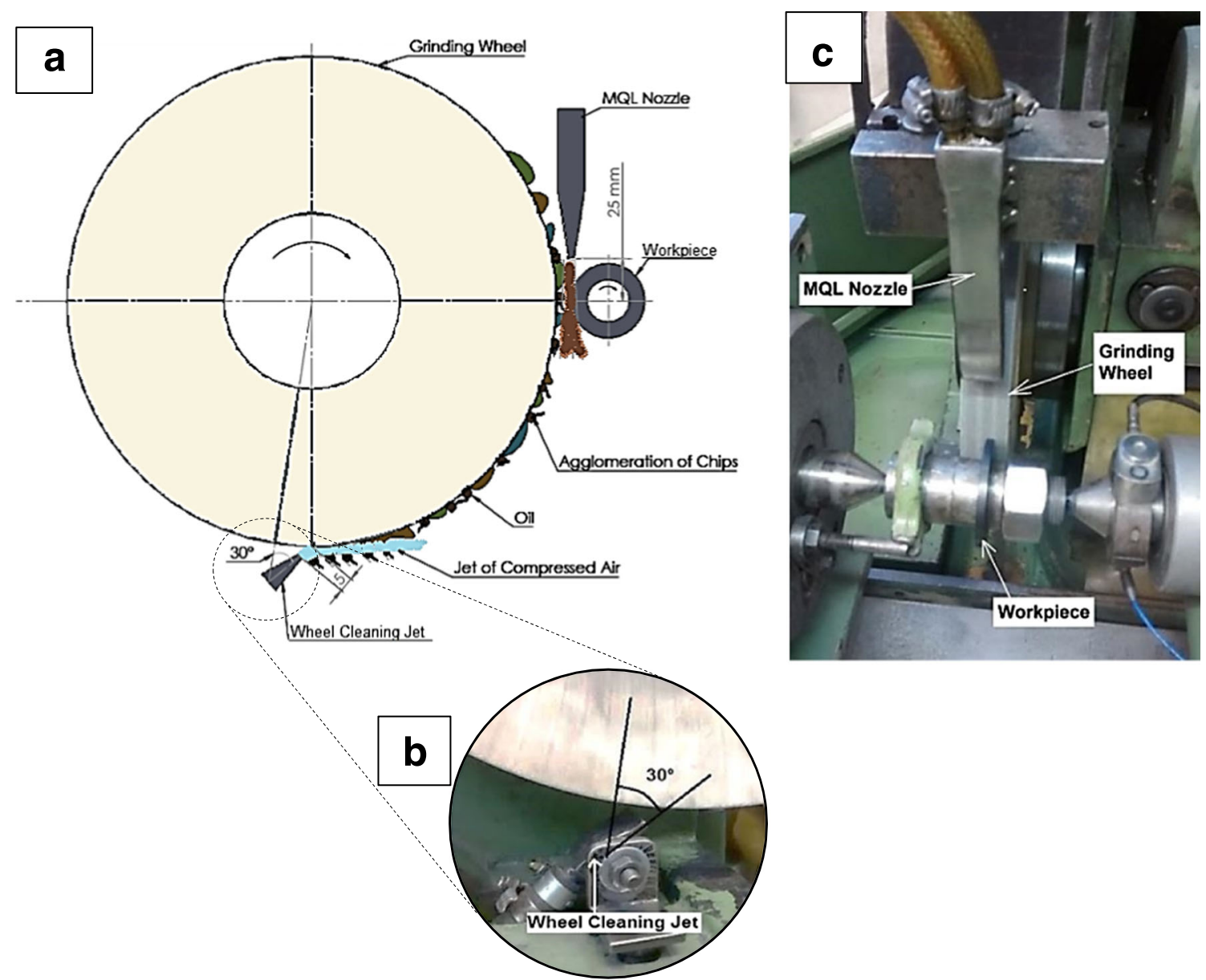

Fig. 2 a Schematic view of the setup of the grinding operation. b Close-up view of the real wheel cleaning system. $\mathbf{c}$ View of wheel-workpiece-coolant delivery system

conventional coolant technique. On the other hand, machining with the MQL + WCJ technique provided roughness values much lower than those recorded after machining with the traditional MQL technique (without the wheel cleaning jet), irrespective of the flow rate tested. Moreover, all three roughness values obtained after tests under application of the MQL + WCJ technique were very close; a two- $\mu \mathrm{m}$ error separated the lowest flow rate $(30 \mathrm{ml} / \mathrm{h}$ that represented the most severe condition - considered near dry machining due to the lowest volume of oil employed) to the highest flow rate $(120 \mathrm{ml} / \mathrm{h})$.
From Fig. 3 can be also observed that Ra values recorded after machining with all the three flow rates employed with the $\mathrm{MQL}+\mathrm{WCJ}$ technique were close to those obtained for conventional coolant technique. Among the coolant flow rate values delivered by the traditional MQL technique, the flow rate of $120 \mathrm{ml} / \mathrm{h}$ outperformed the other ones in term of roughness results. Malkin \& Guo [1] carried out an experimental investigation in grinding of steel with conventional abrasive wheel under various cooling-lubrication conditions and found the highest values for Ra parameter with a flow rate of $30 \mathrm{ml} /$

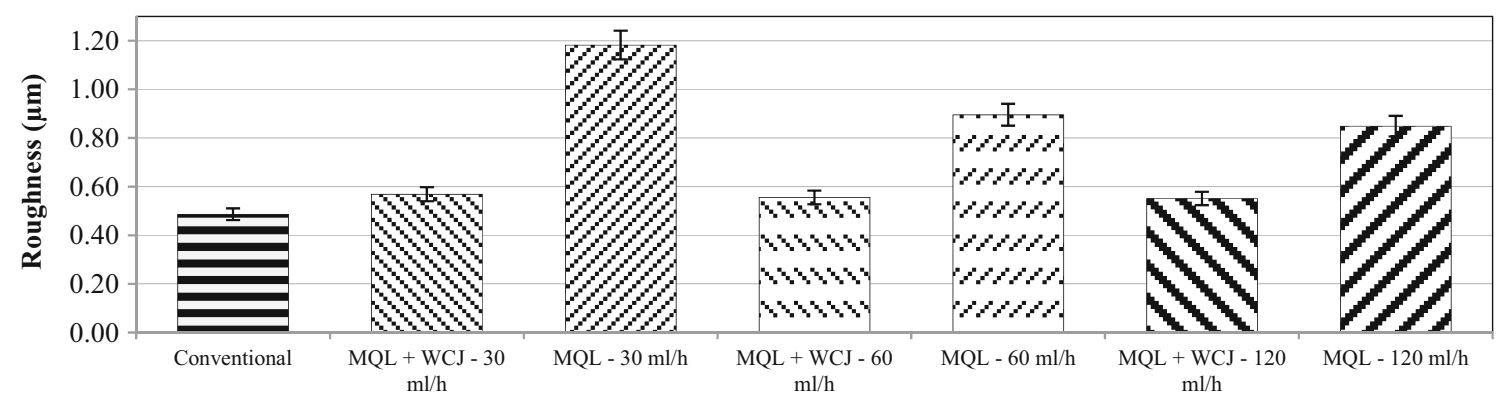

Fig. 3 Values of surface roughness (Ra parameter) recorded after cylindrical grinding of the AISI 4340 steel under different cooling-lubrication techniques and flow rates 
h. They attributed this result to a non-satisfactory coolinglubrication function in machining with this flow rate. According to Ramesh et al. [16], a higher flow rate in MQL technique implies in a higher coolant velocity, that in turn contributes to a combination of improved lubrication effect and better grinding heat dissipation characteristics. Also, according to Daniel et al. [19], the cutting fluid heat transfer increases with the fluid flow velocity. This may explain the superior performance of the flow rate of $120 \mathrm{ml} / \mathrm{h}$ in this work when compared to the lower flow rates $(30$ and $60 \mathrm{~mL} / \mathrm{h})$.

By the fact that the MQL + WCJ technique resulted in lower roughness results, irrespective of the flow rate tested, in relation to those obtained for the traditional MQL technique, it can be inferred that a combination of flow rate, aluminum oxide grinding wheel, and compressed air wheel cleaning jet helped in promoting better evacuation of chips from the contact zone [20], thereby preventing the occurrence of wheel clogging. In addition, since the material removal mechanism in grinding occurs at a micro scale and consists of three phases (rubbing, plowing and cutting), rubbing and plowing stages are highly inefficient in terms of material removal [1, 21], thus only on the cutting phase in fact chip formation takes place. In these phases, high amount of energy is spent in deformation and friction on the surface being machined which is converted to heat within the grinding zone [22]. When the pores of regular abrasive wheels are filled with chips, as observed when grinding with the traditional MQL technique in this current work, the cutting phase is hindered, thereby leading to several negative effects such as poorer surface finish, higher geometric and dimensional errors [14].

According to Oliveira et al. [13], during grinding with conventional abrasive wheels, hot chips are generated, so they have high tendency to lodge into the pores of the grinding wheel. If pores become filled with chips and other impurities during grinding operation, wheel is subjected to the phenomenon called wheel loading that consequently leads to reduction of wheel cutting ability and increases the heat generated during grinding [23]. Klocke [24] recommends that, when tendency to clog the conventional grinding wheel is detected, cleaning nozzles should be employed to rinse the chips and impurities from the wheel pore space during process.

In this current work, by the non-occurrence of the wheel clogging phenomenon after machining with the MQL + WCJ as well as the fact that this cooling-lubricant technique provided the closest Ra parameter value in comparison to conventional coolant technique, it can be inferred that presence of wheel cleaning jet enabled a drastic reduction in the amount of cutting fluid used. It is important to note that machining with the MQL + WCJ under flow rate of 30 and $60 \mathrm{ml} / \mathrm{h}$ generated Ra values close to that obtained for $120 \mathrm{ml} / \mathrm{h}$ and conventional coolant technique. Since the wheel cleaning jet was used, the amount of chips left in the pores was reduced, thereby, providing superior surface quality and accurate workpiece shape because of the less probability for chips indirectly scratch or deform the ground surface. This is in agreement with the recommendation of Klocke [24] to use cleaning nozzles to rinse chips from abrasive wheel during grinding, consequently improving surface quality of a machined component.

Hadad et al. [25] carried out a thermal investigation in grinding various cooling-lubrication conditions (conventional and MQL techniques) and concluded that, despite the fact that MQL provides good lubrication, it cannot meet the grinding cooling requirements in comparison to conventional coolant technique. The authors estimated the average convection heat transfer coefficient in the grinding zone: about $3.7 \times 10^{4} \mathrm{~W} /$ $\mathrm{m}^{2} \mathrm{~K}$ and $900-1200 \mathrm{~W} / \mathrm{m}^{2} \mathrm{~K}$ for conventional coolant and MQL techniques, respectively. This fact can limit the widespread application of traditional MQL in grinding, as can be seen in Fig. 3.

When the MQL-WCJ is employed in high coolant velocity, the grinding heat dissemination characteristics are improved [16]. In this sense, a low-temperature zone exists around the grinding wheel cutting surface which enables retention of grit sharpness [16] and along with the non-occurrence of wheel clogging phenomenon, thereby improving the component surface finish. This was confirmed in this work since lower roughness values were recorded after machining with the MQL-WCJ technique with flow rates in excess of $30 \mathrm{ml} / \mathrm{h}$, results that were also close to conventional technique (Fig. 3).

\subsection{Roundness error}

Figure 4 presents the mean values of roundness errors recorded after cylindrical grinding various cooling-lubrication conditions.

As can been seen from Fig. 4, the lowest roundness error was recorded after machining under the conventional coolant technique (below $2 \mu \mathrm{m}$ ), whereas the highest values were found after machining with the traditional MQL technique with $30 \mathrm{ml} / \mathrm{h}$ flow rate. By considering the roundness error and the standard deviation obtained after machining with the MQL-WCJ technique with flow rates of 60 and $120 \mathrm{ml} / \mathrm{h}$ and comparing them with the value obtained after machining with the conventional coolant technique, it can be inferred that that there is no difference between them. This result shows that the presence of the wheel cleaning jet in the MQL technique can improve the efficiency of the process in terms of roundness under the conditions investigated in this research. Roundness error is directly related to grinding conditions, also thermal damages, mechanical loads, cutting fluid flow and pressure. Roundness error indicates variation of workpiece geometry. Depending on the workpiece material/tool/coolant system and machining parameters employed, any machining process with high generation of heat can cause dimensional and geometrical variation on the workpiece [26]. In this current work was 


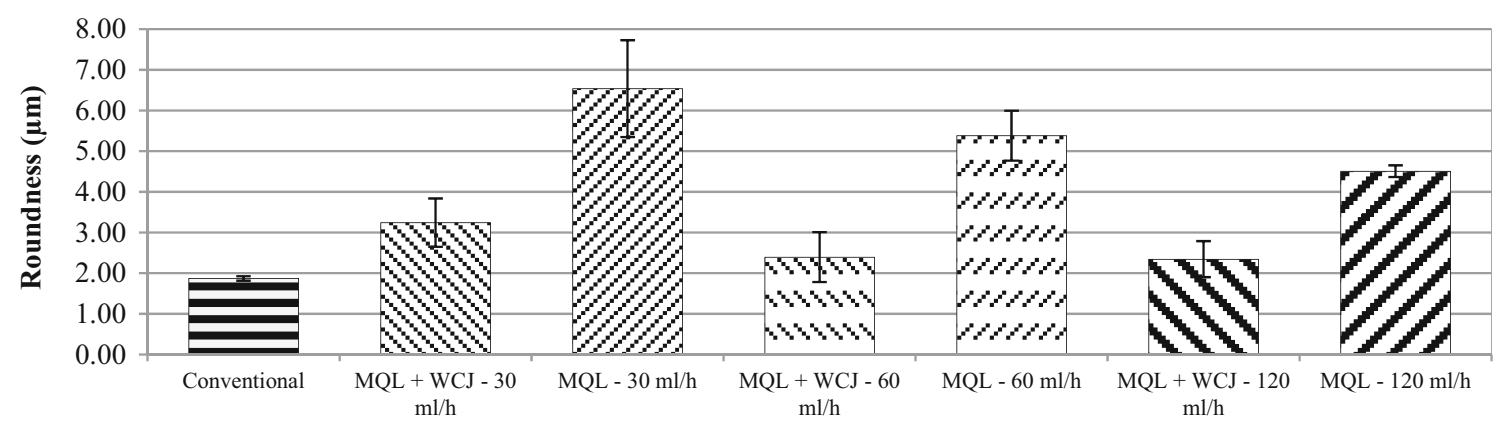

Fig. 4 Roundness errors after cylindrical grinding of an AISI 4340 steel under various cooling-lubrication conditions

observed that machining with the conventional coolant technique exhibit the highest refrigeration capability to remove heat from the cutting zone in comparison with the traditional MQL technique with the lowest amount of neat oil (flow rate of $30 \mathrm{ml} / \mathrm{h}$ ). Ding et al. [27] also reported the highest efficiency of the conventional cooling-lubrication technique in relation to the traditional MQL technique as result of a cleaning system of the wheel during grinding. Similarly, as for surface roughness, the higher the volume of cutting fluid applied, the more effective was the wheel cleaning system to reduce roughness and roundness errors. The behavior of roundness error curve is similar to that for surface roughness (Fig. 3). According to Hadad et al. [26], in their study of the temperature and energy partition during grinding process with MQL technique, lower dissipation of heat occurs in the cutting zone due to the reduction of the amount of cutting fluid and, consequently, the thermal expansion of workpiece results in higher roundness error. Therefore, based on the results obtained for roundness error in this research, it can be concluded that machining with the traditional MQL technique (without the wheel cleaning) at a flow rate of $120 \mathrm{ml} / \mathrm{h}$ outperformed the other flow rate values employed with this technique, while considering the MQL + WCJ technique (with wheel cleaning jet) exhibited superior performance after machining at flow rates in excess of $30 \mathrm{ml} / \mathrm{h}$.

During the grinding runs, the quantity of the chips generated increases until they lodge in the wheel pores, causing workpiece elastic and plastic deformation, and consequently increases friction in contact zone. Since cutting forces are increased, the workpiece finishing is impaired and roundness errors are increased, as well as wheel wear. High temperatures in cutting zone cause the uncontrolled mechanical expansion and retraction of the workpiece which are the most outstanding causes of roundness errors [28]. By the fact that, in the current work, the traditional MQL technique is not able to remove efficiently the heat from the cutting zone, the roundness errors are increased, as can be seen in Fig. 4. The ineffectiveness of cleaning chips from the cutting zone when the traditional MQL technique was employed produced adverse effects to the cutting phase, it led to higher geometric errors, including higher roundness measured values [14]. Furthermore, machining with the MQL + WCJ technique under flow rates in excess of $30 \mathrm{ml} / \mathrm{h}$ provided superior tribological properties in the cylindrical grinding of AISI 4340 steel under the conditions employed in this work, therefore the chip removal capacity was more efficient than that observed after machining under the lowest flow rate of fluid $(30 \mathrm{ml} / \mathrm{h})$ and without the air cleaning (irrespective of flow rate tested) delivered by the traditional MQL technique (which were probably impaired by the wheel clogging).

\subsection{Diametrical wheel wear}

As cutting forces and machining quality are determined by cutting tool performance, it is fundamentally important the study of wheel wear behavior, aiming at the high efficiency of grinding process [29]. Figure 5 shows the diametrical abrasive wear values measured in the aluminum oxide grinding

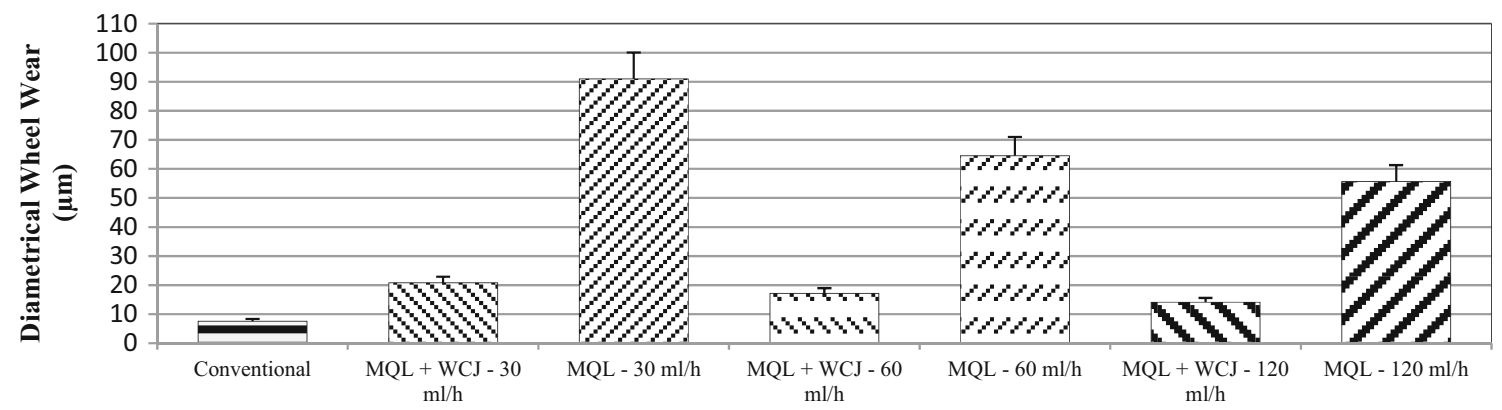

Fig. 5 Diametrical wear of aluminum oxide wheel after machining after grinding AISI 4340 steel under different cooling-lubrication techniques and flow rates 
wheel after cylindrical grinding of an AISI 4340 steel grade under different cooling-lubrication conditions. The lowest wheel wear values were recorded after machining under the conventional coolant delivery technique and, again, this condition outperformed the both traditional MQL and MQL + WCJ techniques, irrespective of the flow rate employed, similarly to results obtained in terms of roughness and roundness (as shown in Figs. 3 and 4, respectively). In general, higher volume of oil represents reduction in grout formation to a greater extent. This trend allows inferring the coherence among the results for the wheel wear, roundness and roughness, since the highest roughness values correspond to the machining condition that presented the highest diametrical wheel wear.

According to Silva et al. [29], diametrical wheel wear tend to be low when cooling-lubrication functions are improved by the cutting fluid action. In fact, the decrease of friction among abrasive grains, workpiece and chips permits abrasive grains to stay longer attached to the bond, consequently minimizing wheel wear rate. In addition, diametrical wheel wear is related to the following two causes: thermal deterioration and high mechanical loads to which the grinding wheel is subjected. When thermal dissipation occurs in the cutting region, the loss of bond resistance decreases, along with the decrease of diametrical wheel wear [1]. According to Walker [30], optimization of MQL technique is recommended for jobs that are repeated or that are run for long time, like in grinding operation, for instance. This author also states that one of the advantages of this technique is that the swarf is flushed away from the grinding zone, thereby avoiding gumming.

\subsection{Grinding power}

In Fig. 6 are shown the grinding power results recorded during machining of AISI 4340 steel under different coolinglubrication conditions. It can be observed that the behavior for grinding power is very similar to that for diametrical wheel wear, roughness and roundness parameters. When the lubrication property of cooling-lubrication technique is reduced, grinding forces increase, then more power is required to perform cutting. Ruzzi et al. [31] reported that the when a cooling capacity in grinding of hardened steel with conventional abrasive wheel is achieved, the workpiece material temperature will be kept in lower levels, so its mechanical resistance will be retained, which in turn, hampers the cutting action by the wheel grits, thereby requiring higher grinding power.

The presence of cleaning system in the MQL + WCJ contributed to bring closer the MQL technique to the conventional one in terms of grinding power consumed in the process, as well wheel wear, roundness and roughness.

By considering the grinding process with the traditional MQL technique as shown by 3 cooling-lubrication conditions, the oil droplets are directly delivered into the cutting area and deposited onto the abrasive wheel's surface, forming a lubricant film (boundary lubrication film). By increasing the oil flow, the droplet deposition rate onto the wheel's surface increases and the friction is reduced in the wheel-workpiece interface. So, it can be inferred that grinding power decreases as oil flow increases, as a result of the increase of the refrigeration capability of the coolant to remove the heat from the cutting zone.

Barczak et al. [32] carried out a study in plane surface grinding of several steels grades with alumina abrasive wheel and under two different coolant-lubrication techniques (conventional (wet or flood) and traditional MQL). They reported that the MQL technique outperformed the conventional technique in terms of cutting forces and grinding power. The MQL technique yielded the lowest forces, about $42 \%$ lower than for conventional technique. These authors attributed this fact to the results of hydrodynamic effects increasing power consumption when machining under the conventional coolant technique and the improved lubrication properties of the MQL oil.

\subsection{Optical microscopy and microhardness}

Aiming to detect possible alteration of workpiece microstructure after a grinding process under different coolinglubrication techniques, a specimen for each condition tested (which presented the lower standard deviation for roughness and roundness) was chosen for the analyses of the optical microstructure and microhardness. No surface burns or

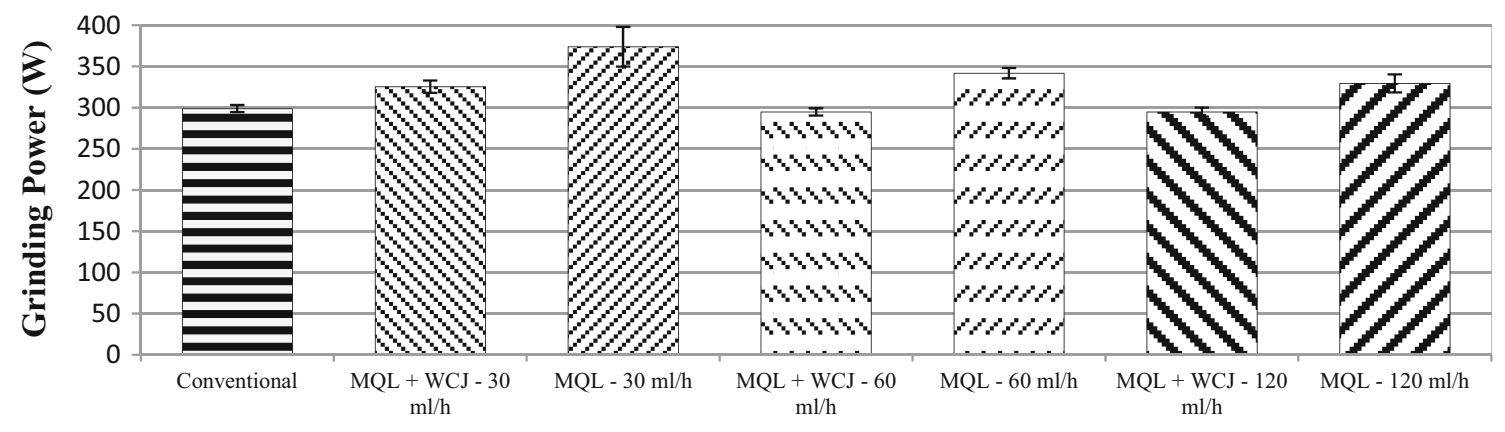

Fig. 6 Grinding power consumed during grinding AISI 4340 steel under different cooling-lubrication techniques and flow rates 
tempering occurred on the surfaces and subsurfaces of the ground materials, irrespective of the coolant-lubrication technique employed. According to Klocke et al. [33], nonoccurrence of microstructural alteration is a crucial requirement for industries, since the following parameters are guaranteed such as: microstructural quality, mechanical properties of project and machining efficiency. Furthermore, this practice allows avoiding economic loss because of the fact that grinding is the final process in the productive cycle.

Figure 7 shows the Vickers microhardness results recorded as a function of each cooling-lubrication condition employed. Considering the reference value for microhardness measured prior to grinding tests is near $697 \mathrm{HV}$, it can be seen from Fig. 7 that workpieces experienced a slight drop in hardness up to $60 \mu \mathrm{m}$ at a depth below machined surface for all the conditions investigated in this work. The highest relative drop in hardness was observed after machining with the traditional MQL technique with $30 \mathrm{ml} / \mathrm{h}$, which is characterized as the most severe grinding condition, but that represents about $1.97 \%$ error in relation to the prior measured value before grinding. Such percent error can be considered low and insignificant to represent any microstructure alteration. Since one of the forms to detect thermal damages in machined components is by observation of microstructure and properties, for instance measuring the microhardness below the machined surface, as shown in Fig. 7, and by machined surface and subsurface examinations, it can be inferred that there was no metallurgical alterations in workpiece microstructure due to grinding temperatures in all of the cooling-lubrication conditions tested in this work.

\section{Conclusions}

The following conclusions can be drawn from this research:

- Considering the geometric parameters, roughness and roundness, the traditional MQL technique (without cleaning system) showed inferior performance than conventional coolant technique. On the other hand, the application of the MQL + WCJ technique (with the wheel cleaning system) under flow rate in excess of $30 \mathrm{ml} / \mathrm{h}$ represented a significant improvement in terms of roughness and roundness due to the improved coolinglubrication properties. Results from this condition were very close to those recorded by the conventional coolant technique;

- Machining under the traditional MQL technique also exhibited inferior performance in comparison to conventional coolant technique in terms of wheel wear and power consumed. However, again, machining with the MQL + WCJ technique resulted in reduction of the values of wheel wear and power consumed and they were as close as those obtained for conventional coolant technique, therefore showing that efficiency of the traditional MQL technique can be improved if a wheel cleaning jet is employed;

- Although no surface burns or tempering occurred on the surfaces and subsurfaces of the ground materials, irrespective of the cooling-lubrication technique employed, a slight drop in hardness up to $60 \mu \mathrm{m}$ at a depth below the machined surface was observed after machining with the traditional MQL technique under the lowest flow rate of $30 \mathrm{ml} / \mathrm{h}$;

- Machining with the MQL + WCJ technique proved to be a viable alternative to the conventional coolant technique in cylindrical grinding of AISI 4340 steel with an aluminum oxide wheel under the conditions investigated due to similar results for most of output variables analyzed. Moreover, the MQL + WCJ technique promotes a cleaner environment and requires lesser consumption of fluid than conventional coolant technique. Under some specific conditions, the MQL + WCJ technique has proved to be similar or outperform the conventional coolant technique.
Fig. 7 Microhardness below the ground surface after grinding AISI 4340 steel under different cooling-lubrication techniques and flow rates

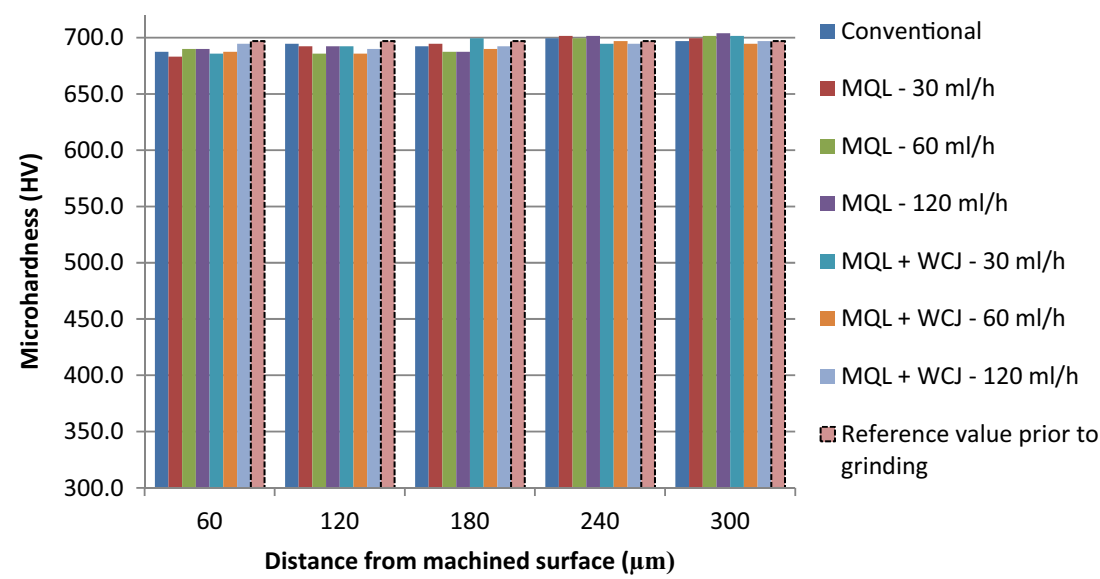


Acknowledgements Special thanks are due to FAPESP (State of São Paulo Research Assistance Foundation-Process Number 2015/091977), FAPEMIG, and CNPq (National Counsel of Technological and Scientific Development) for supporting this work. One of the authors thank CAPES for the financial support given by a PNDP project-post doctoral scholarship at the Post-Graduate Program of Electrical Engineering of FEB-UNESP-BAURU (2016-2017).

\section{Compliance with ethical standards}

Conflict of interest The authors declare that they have no conflict of interest.

\section{References}

1. Malkin S, Guo C (2008) Grinding Technology: Theory and applications of machining with abrasives. Industrial Press, New York, $p$ 372

2. Nguyen TA, Butler DL (2005) Simulation of precision grinding process, part 1: generation of the grinding wheel surface. Int $\mathrm{J}$ Mach Tools Manuf 45(11):1321-1328. https://doi.org/10.1016/j. ijmachtools.2005.01.005

3. Marinescu ID, Rowe WB, Dimitrov B, Inasaki I (2013) Tribology of abrasive machining processes, $2^{\mathrm{a}} \mathrm{ed}$. edn. William Andrew Inc, Norwich

4. Sharma VS, Singh G, Sørby K (2014) A review on minimum quantity lubrication for machining processes. Materials and Manufacturing Processes 30(8):935-953

5. Wang YG, Li CH, Li BK, Yang M, Zhang XW (2015) Advances and recent patents in the field of grinding temperature measurement methods. Bentham Science 8(1):55-68

6. Guo C, Shi Z, Attia H, Mcintosh D (2007) Power and wheel wear for grinding nickel alloy with plated CBN wheels. CIRP Ann Manuf Technol 56(1):343-346. https://doi.org/10.1016/j.cirp. 2007.05.079

7. Irani RA, Bauer RJ, Warkentin A (2005) A review of cutting fluid application in the grinding process. Int J Mach Tools Manuf 45(15): 1696-1705. https://doi.org/10.1016/j.ijmachtools.2005.03.006

8. Dhar N, Islam S, Kamruzzaman M (2006) Effect of minimum quantity lubrication (MQL) on tool wear, surface roughness in turning AISI-4340 steel. J Mater Process Technol 172(2):299-304. https://doi.org/10.1016/j.jmatprotec.2005.09.022

9. HSE - Health and Safety Executive (2011) Working safely with metalworking fluids - A guide for employees. INDG365-08/11. http://www.hse.gov.uk/pubns/indg365.pdf. Accessed 16 May 2017. http://www.nationalarchives.gov.uk/doc/opengovernment-licence/version/3/- - The UK Government Licensing 5:2011

10. Sanchez JA, Pombo I, Alberdi R, Izquierdo B, Ortega N, Plaza S, Martineztoledano J (2010) Machining evaluation of a hybrid MQLCO2 grinding technology. J Clean Prod 18:1840-1849

11. Dudzinsk D, Devillez A, Moufki A, Larrouque're D, Zerrouki V, Vigneau JA (2004) Review of developments towards dry and high speed machining of Inconel 718 alloy. Int J Mach Tool Manu 44(4): 439-456. https://doi.org/10.1016/S0890-6955(03)00159-7

12. Zhang YB, Li CH, Jia D, Zhang DK, Zhang XW (2015) Experimental evaluation of MoS2 nanoparticles in jet MQL grinding with different types of vegetable oil as base oil. J Clean Prod 87: 930-940

13. Oliveira DJ, Guermandi LG, Bianchi EC, Diniz AE, Aguiar PR, Canarim RC (2012) Improving minimum quantity lubrication in CBN grinding using compressed air wheel cleaning. J Mater
Process Technol 212(12):2559-2568. https://doi.org/10.1016/j. jmatprotec.2012.05.019

14. Cameron A, Bauer R, Warkentin A (2010) An investigation of the effects of wheel cleaning parameters in creep-feed grinding. Int $\mathrm{J}$ Mach Tools Manuf 50(1):126-130. https://doi.org/10.1016/j. ijmachtools.2009.08.008

15. Ramesh K, Yeo SH, Zhong ZH, Huang H (2003) Ecological grinding with chilled air as coolant. Proc Instn Mech Engrs PartB: J Eng Manuf 217:409-419

16. Ramesh K, Huang H, Yin L (2004) Analytical and experimental investigation of coolant velocity in high speed grinding. Int J Mach Tool Manuf 44(10):1069-1076

17. Barros BG, da Silva T, Canarim RC, Aguiar PR, Bianchi EC (2014) Utilization of teflon and aluminum oxide for wheel cleaning in minimum quantity lubrication (MQL) grinding. Mater Res 7(1): 23-32

18. Silva LR, Correa ECS, Brandao JR, de Avila RF (2013) Environmentally friendly manufacturing: behavior analysis of minimum quantity of lubricant $-\mathrm{MQL}$ in grinding process. J Clean Prod 31

19. Daniel CM, KVC R, Olson WW, Sutherland JW (1996) Effect of cutting fluid properties and application variables on heat transfer in turning and boring operations. Japan/USA Symp Flex Autom 2: $1119-1126$

20. Marinescu ID, Hitchiner M, Uhlmann E, Rowe WB, Inasaki I (2007) Handbook of machining with grinding wheels. CRC Press, Taylor \& Francis Group, USA, $596 \mathrm{p}$

21. Chen X, Öpöz TT (2016) Effect of different parameters on grinding efficiency and its monitoring by acoustic emission. Prod Manuf Res 4(1):190-208. https://doi.org/10.1080/21693277.2016.1255159

22. Guo C \& Malkin S (1995) Analysis of energy partition in grinding. Journal of Engineering for Industry 117(1):55-61

23. Rufe PD (2005) Fundamentals of manufacturing supplement. Society of Manufacturing Engineers 234:2005

24. Klocke F (2009) Manufacturing processes 2: grinding, honing, lapping. Springer-Verlag, Berlin Heidelberg, 433p, 2009

25. Hadad M, Sadeghi B (2012) Thermal analysis of minimum quantity lubrication-MQL grinding process. Int J Mach Tool Manu 63:1-15. https://doi.org/10.1016/j.ijmachtools.2012.07.003

26. Hadad MJ, Tawakoli T, Sadeghi MH, Sadeghi B (2012) Temperature and energy partition in minimum quantity lubrication-MQL grinding process. Int J Mach Tool Manu 54-55:10-17

27. Ding K, Fu Y, Su H, Gong X, Wu K (2014) Wear of diamond grinding wheel in ultrasonic vibration-assisted grinding of silicone carbide. Int J Manuf Technol 71(9-12):1929-1938

28. Souza N, RE C, PR A, MH S, EC B (2004) Analysis of diametrical wear of grinding wheel and roundness errors in the machining of steel VC 131. J Braz Soc Mech Sci Eng:209-212

29. Silva LR, Bianchi EC, Fusse RY, Catai RE, Franca TV, Aguiar PR (2007) Analysis of surface integrity for minimum quantity lubricant-MQL in grinding. Int J Mach Tool Manu 47(2):412-418. https://doi.org/10.1016/j.ijmachtools.2006.03.015

30. Walker T (2013) The MQL handbook - a guide to machining with minimum quantity lubrication, Unist, Inc V1.0.3, 43p, 2013

31. Ruzzi RS, Belentani RM, De Mello HJ, Canarim RC, D'Addona DM, Diniz AE, De Aguiar PR, Bianchi EC (2016) MQL with water in cylindrical plunge grinding of hardened steels using CBN wheels, with and without wheel cleaning by compressed air. Int J Adv Manuf Technol 90(1-4):329-338

32. LM B, ADL B, MN M (2010) A study of plane surface grinding under minimum quantity lubrication (MQL) conditions. Int J Mach Tool Manu 50:977-985

33. Klocke F, Brinksmeier E, Weinert K (2005) Capability profile of hard cutting and grinding process. CIRP Ann Manuf Technol 54(2): 22-45. https://doi.org/10.1016/S0007-8506(07)60018-3 